\title{
A rima nos cantos populares: contribuições para o rimário brasileiro
}

\author{
Álvaro Silveira Faleiros*
}

\section{As fronteiras}

Estudar um fenômeno como o uso da rima nos cantos populares do Brasil é uma tarefa gigantesca, porém necessária, devido à sua riqueza e ao desconhecimento do assunto que ainda impera. Nas linhas que seguem, fazemos um estudo apenas das características presentes na rima da poesia popular e que não se manifestam na poesia "culta" (de tradição escrita), uma vez que esses traços encontram-se apagados dos tratados de metrificação, assim como dos dicionários de rima, como se o português falado não produzisse formas próprias de poesia.

Entretanto, muitos desses traços caracterizam parte importante da poesia cantada no Brasil, manifestação artística por meio da qual o horizonte da rima e da poesia constantemente se renova e se amplia. Como já afirmava Erza Pound": "A música apodrece quando se afasta da dança. A poesia se atrofia quando se afasta muito da música" e essa musicalidade se projeta na voz.

Dessa maneira, nosso estudo visa a catalogar as principais contribuições fonéticas ${ }^{2}$ que se devem, sobretudo, ao caráter oral dessa poesia. Para tal, é necessário, primeiramente, definir o que entendemos por rima.

\section{A rima}

Entende-se por rima a repetição, no final dos versos de um poema, de uma série de sons iguais ou similares. A rima é, como afirma $\mathrm{Chociay}^{3}$, "um processo de reiteração fônica que ocorre geralmente, a partir da última vogal forte de cada verso". A repetição desse conjunto de sons, segundo Nóbrega ${ }^{4}$, pode se resumir a um único som, consonântico ou vocálico, ou se estender a um conjunto mais amplo de fo-

* Professor da UnB e Doutor em Letras pela FFLCH-USP

1 Pound, Ezra. ABC da Literatura, São Paulo, Cultrix, 1977, p. 61.

2 As contribuições sintáticas e lexicais, também relevantes na ampliação do rimário brasileiro, serão tratadas em estudos futuros.

3 Chociay, Rogério. Teoria do verso. São Paulo, McGraw-Hill do Brasil, 1974, p. 174.

4 Nóbrega, Mello. Rima e poesia. Rio de janeiro: I.N.L., 1965. 
nemas, combinados de diferentes formas. Essa reiteração fônica, que se dá entre dois ou mais versos, pode ocorrer tanto dentro como no final dos mesmos.

Nas linhas que seguem concentramo-nos apenas nas reiterações fônicas em que há a repetição de todos os fonemas a partir da última vogal tônica de cada verso, ou seja, nas rimas chamadas de consoantes ou de soantes. Nossa escolha deve-se ao fato de que são essas hoje as rimas mais praticadas na poesia popular e são elas, também, que encontram-se sistematizadas nos dicionários de rimas. A elas corresponde, pois, o que comumente chama-se rima.

Para que ocorra uma rima consoante completa (ou perfeita ${ }^{5}$ é necessária a reiteração total de sons a partir da última vogal tônica do verso. Há, porém, uma antiga discussão sobre o que caracteriza a reiteração total de sons, já que a grafia nem sempre corresponde ao que se pronuncia. Esta é, aliás, uma fronteira importante entre os estudos clássicos da rima e os estudos lingüísticos. Nestes, a rima, por ser um fenômeno fonético, é classificada a partir da fala e não da grafia.

\section{As rimas aparentemente incompletas}

Mattoso Câmara $\mathrm{Jr}^{6}$ identificou um conjunto de rimas que são apenas aparentemente incompletas (Câmara Jr. utiliza o termo imperfeitas). Esse conjunto de rimas envolve, de um lado, vocábulos com a presença, em sua grafia, do par opositivo $o / u$. E, de outro lado, vocábulos com a presença, em sua grafia, do par opositivo e/i. Nesses dois casos, em português, encontramo-nos, muitas vezes, diante do mesmo som.

No primeiro par, temos palavras em que a vogal $o$, em posição fraca, corresponde, de fato, ao som [u]. Como nas rimas mágoa/água, árgus/largos, pérolas/cérulas. 0 mesmo ocorre com o segundo par, em que a vogal e se pronuncia [i] em sílaba postônica, como em cálix/vales, área/ária, satélite/impele-te, moléstia/veste-a, espécie/tece.

Há ainda a fusão de sons quando do encontro de duas vogais $o$, como em risonhos/reponho-os. A vogal $i$ e a vogal $e$ podem também se fundir, como em visse/superfície, planície/velhice, produzindo, assim, rimas em -isse.

Câmara Jr. trata, por fim, dos ditongos. Por um lado, os ditongos presentes em rico/oblíquo, acabou-se/doce e vou/avô, em que o $u$ se funde ao $o$, e que produzem, respectivamente, rimas em -ico, -ôce e -ô e, por outro lado, os di-

5 Seguindo as orientações de Mello Nóbrega (1965), preferimos o termo rima completa, ao invés de rima perfeita, por ser o primeiro um termo mais técnico e menos valorativo, já que acreditamos que a "perfeição" de um poema se deve ao seu conjunto e não à manutenção rígida de uma regra.

6 Câmara, Joaquim Mattoso. "A rima na poesia brasileira”. Para o Estudo da Fonêmica Portuguesa. Rio de Janeiro, Simões, 1953, pp.119-165. 
tongos existentes em vejo/beijo, acho/baixo, em que a vogal $i$ desaparece diante das consoantes alvéolo-palatais, já que o ponto de articulação do $i$ e dessas consoantes é o mesmo e que resultam nas rimas soantes -ejo e -acho.

A vogal $i$, entretanto, não se anula quando precede consoantes anteriores, como nos pares foi-se/doce, preta/ deita, meiga/chega, que são rimas incompletas.

De todo modo, o que nos parece revelador nesse estudo é que, ao debruçar-se sobre os aspectos da fala, Mattos Câmara Jr. identificou uma série de relações fônicas que permitem um melhor entendimento das escolhas feitas pelos poetas que, nos casos acima, procuraram uma reiteração completa dos sons e não uma nuança fônica ou uma mudança no padrão sonoro, como sugere a grafia.

Ressaltamos, ainda, que há uma diferença importante entre as semelhanças fônicas existentes em pares como mágoas/águas, área/ária, vejo/beijo, vou/avô e aquelas que se encontram em pares como acho/baixo, acabou-se/doce ou ainda o par rico/oblíquo.

Os quatro primeiros pares são considerados equivalências fônicas características da língua portuguesa tanto na norma popular quanto na norma culta, tanto é que nos Dicionários de Rimas, desde o de Costa Lima, do século XIX, considera-se essas rimas como "rimas perfeitas". Os outros três pares - e, sobretudo, o último - não são unanimemente aceitos como característicos da norma culta, tanto é que não aparecem como equivalentes em todos os dicionários de rimas consultados? ${ }^{7}$.

De fato, a questão que se coloca é, a partir de que norma considera-se a língua e, neste trabalho, indicar as rimas que constituem-se a partir da fala popular. É, pois, necessário, inicialmente, indicar as contribuições fonéticas advindas desse registro.

\section{Contribuições fonéticas dos falares brasileiros}

Desde o século XIX, uma série de pesquisadores estuda e compila as características da fala popular brasileira. 0 primeiro a publicar em livro suas considerações e traçar um panorama dos trabalhos que lhe precederam foi Sílvio Romero ${ }^{8}$.

7 Foram consultados os dicionários de rimas de Lima, Costa. Dicionário de rimas. Porto, Lello, s.d.; Castelões, Visconde de. Dicionário de rimas. Porto, Domingos Barreira, s.d.; Castro, Almerindo Martins de. Dicionário de rimas. Rio de Janeiro, Científica, s.d.; Passos, Guimarães. Dicionário de rimas. Rio de Janeiro, Francisco Alves, 1913; Fernandez, José Augusto. Dicionário de rimas. 6. ed. Rio de Janeiro, Record, 1999. 0 único par que não consta em nenhuma das obras é a rima rico/oblíquo.

8 Sílvio Romero. "Transformações da língua portuguesa na América", Estudos de poesia popular do Brasil. Petrópolis, Vozes,1977, p.234-354. 
Na parte dedicada às alterações fonéticas, Sílvio Romero $^{9}$ tece algumas considerações sobre processos que atuam no final dos vocábulos.

Quanto às VOGAIS, afirma:

- José de Alencar já havia notado a nossa tendência de pronunciar o e final como $i$ e o $o$ como $u$.

- No Brasil, no ditongo ai, pronunciamos cáixa, báixo, quase como caxa, baxo, abrindo o a e fazendo soar pouco o $i$.

Em relação às CONSOANTES:

- A supressão de uma ou mais letras no final das palavras (aférese) é usual entre os brasileiros, principalmente caboclos e caipiras, que dizem botá, ardê, subi, comendo invariavelmente os $r r$ finais.

- Não é só o $r$ final que o povo suprime, o mesmo faz com qualquer outra consoante; ex.: home, corage, virginá, generá, por homem, coragem, virginal, general.

- A permuta do $l$ pelo $r$, a apócope do $r$, a queda da molhada $l h$, "[...] porquanto encontramos entre o povo vozes como estas: farsa, carça, teia, teiado, muié,[...] em vez de falsa, calça, telha, telhado, mulher".

Sílvio Romero organiza, no mesmo volume, um "pequeno glossário de termos estropiados pelo jargão das classes baixas", do qual destacamos: mesmo-mêmo; bênçãobença; senhor-sinhô, senhora-sinhá, pássaro-passo, árvorearve. Trata-se, na maioria das vezes, de um conjunto de transformações comuns aos falares do Brasil.

No início do século XX, outros estudos mais sistemáticos ${ }^{10}$, foram realizados, nos quais nos autores procuraram, não apenas identificar as características da fala popular, mas explicá-las por meio da filologia e da influência de línguas indígenas e africanas. Desse modo, Marroquim, por exemplo, identificou, já nas origens do português, transformações do $l$ em $r$, como em platu(m)-prato, nobile $(m)$-nobre.

Em relação ao "dialeto caipira”, há alterações, no final das palavras, ainda não mencionadas e que foram identificadas por Amaral:

9 As considerações de Sílvio Romero, aqui resumidas, foram selecionadas por serem aquelas que tratam de mudanças fonéticas nos finais das palavras e, dessa maneira, influenciam diretamente a rima. As contribuições sintáticas e lexicais serão tratadas em trabalhos futuros.

10 Amaral, Amadeu. O dialeto caipira. São Paulo, "0 Livro", 1920; Nascentes, Antenor. O linguajar carioca. 2. ed. Rio de Janeiro, Rex, 1953; e Marroquim, Mário. A língua do Nordeste. São Paulo, Cia Editora Nacional, 1934. 
No que se refere às VOGAIS:

- Segundo o autor, "Nos vocábulos esdrúxulos, a tendência é para suprimir a vogal da penúltima sílaba e mesmo toda esta, fazendo grave o vocábulo (ridico = ridículo, legite = legítimo, $\operatorname{cosc} a=$ cócegas, musga = música)". Acrescente-se ${ }^{11}$ relâmpago-relampo, mármore-marme, pólvora-porva, pêssego-pesco, além de pássaro-passo, árvore-arve já identificados por Sílvio Romero.

Note-se que, de fato, essa tendência já é encontrada na formação do latim vulgar. Entretanto, Amaral, fala em supressão da penúltima sílaba, quando, na verdade, trata-se de supressão de vogais de sílabas postônicas e mesmo de todas elas, e não necessariamente apenas da penúltima (casos de síncope e de apócope).

- O grupo vocálico õu (om), “nas palavras bom, tom, som muda-se em ão: bão, tão, são"12.

\section{Quanto às CONSOANTES:}

- A consoante $d$ cai, quase sempre, na sílaba final das formas verbais em -ndo, como em anadano, veno, caino e pôno para andando, vendo, caindo e pondo.

Antenor Nascentes ${ }^{13}$, mais sistemático que seus antecessores, permite identificar, entre outros, os seguintes processos que influenciam os segmentos rimantes:

Quanto às VOGAIS:

- 0 a pode transformar-se em e: inveja-inveje.

- Há desnasalizações do a (e do e): órfã-orfa, imã-ima, (viage, vertige, home, onte...)

Já nas SEMICONSOANTES:

- 0 y postônico, precedendo imediatamente a vogal final, é absorvido: matéria-matera, história-histora, dúzia-duza, polícia-puliça, glória-glora, espécie-espece, superfície-superfice, colégio-culejo, necrotério-nicrotero.

- $0 w$ é atraído ou absorvido: régua-reuga, estátua-estauta, tábua-tauba ou taba, nódoa-noda.

- 0 grupo ua pode transformar-se em o: quanto-conto, quando-condo.

11 Cf. Nascentes, 1953, p.64.

12 Idem, p.36.

13 Idem, p.27-70. 
Nos DITONGOS em:

- $\tilde{a} o$, final e átono, perde o primeiro elemento: órfão-orfo, órgão-orgo, sótão-soto. Nascentes assinala que o ditongo, em bênção-bença, reduz-se a $a$ devido à flexão feminina.

- $\tilde{a} o$, grafado -am, nos verbos, dá um ou 0 : foram-forumforo.

As CONSOANTES passam pelas seguintes transformações ainda não assinaladas:

- $l$ final, além de ser absorvida, pode vocalizar-se: qualquá-quau, papel-papé-papéu, Brasil-Brasi-Brasiu.

- $0 n$ palatal $(n h)$ pode se despalatalizar: companhia-compania.

- Consoante seguida de $r$, ele tende a desaparecer: compadre-cumpade, negro(a)-nego(a), registro-registo, quatro-quato.

- Redução do gn a $n$ : repugnar-repuná, maligno-malino.

Nascentes faz, em seguida, referência aos "diversos fenômenos fonéticos", a maioria dos quais já estudados (aférese, síncope, apócope, (des)nasalização, (des)palatalização). No que se refere aos segmentos rimantes, cabe-nos, por fim, ressaltar os seguintes fenômenos fonéticos:

- Epêntese, em geral de $r$ : leque-lecre, lagosta-lagostra, estalar-estralá.

- Paragoge, em palavras terminadas em plosivas: sob-sôbi, Isaac-Isaque.

- Na palavra boi pode haver paragoge (o) para marcar o gênero: boi-boio.

- Metátese (interversão): lagarta-largata, teatro-triato, proporção-porpoção.

Enfim, Marroquim ${ }^{14}$, em seu estudo sobre a língua do Nordeste, não aponta nenhum fenômeno que não tenha sido aqui enumerado - exceto algum caso particular, ex. regimerijume - o que evidencia o fato de que esses fenômenos são, em sua grande maioria, comuns a todas as regiões do país, uma vez que retiramos os exemplos de estudos sobre o linguajar carioca e o dialeto caipira. É claro que, em algumas regiões, o mesmo fenômeno pode aplicar-se de modo mais amplo ou não. Assim, o caipira vai ampliar o uso do 
$r$ (rima, por exemplo, ir/Brasir), já no Nordeste a rima seria em $i$. Procuramos apontar essas distinções na apresentação dos textos, porém, antes de fazê-lo, é necessário distinguir os fenômenos fonéticos já incorporados à poesia "culta" daqueles específicos da fala popular.

\section{Rima e fonética na poesia culta e na poesia popular}

Dentre os traços acima, há, de um lado, aqueles característicos da fala do português, que se encontram, inclusive, sistematizados nos dicionários de rimas e que são utilizados freqüentemente como recurso na poesia escrita e, do outro, as características fonéticas específicas do falar popular do Brasil, consideradas como "erros" de acordo com o "padrão" do português falado.

Fazem parte dos traços gerais da fala do português, os processos fônicos tratados por Matoso Câmara e alguns encontrados em Nascentes, todos eles já assimilados na poesia de língua culta, desde o século XIX, dentre os quais destacamos:

- Transformação do e e do o postônicos em e e $u$, respectivamente;

- Supressão do $i$ e do u nos ditongos (beijo-bejo, baixobaxo, caixa-caxa, pouco-poco, acabou-se-acabôce);

- Absorção do $i$ nos ditongos suprefice-superfície, planiceplanície;

- Ditongação do $a$ e do e, diante de $s$ e $z$ (paz-paiz, masmais, vez-vêis, mês-mêis).

- Vocalização da $l$ final (qual-quau, papel-papéu, BrasilBrasiu);

Já os outros traços, proscritos em um registro formal, são altamente produtivos na poesia popular de todas as regiões do Brasil. Dessa maneira, identificaremos, em poemas populares, rimas nas quais se estabeleçam reiterações fônicas entre termos usuais da língua e outros com as características da fala popular acima descritas, ou seja, rimas que só são possíveis graças às transformações fonéticas.

Ao longo de nosso estudo, notamos que a grande maioria dos fenômenos fonéticos diz respeito, de fato, às soantes, ou seja, é, sobretudo, por meio de transformações que envolvem as laterais, as vibrantes e as nasais que as possibilidades rímicas da poesia popular são ampliadas. Desse modo, na apresentação, iniciamos com as transformações especificamente vocálicas e consonantais para, por fim, tratar das modificações que envolvem as soantes. 
Os registros da poesia popular: da fala à escrita

Nos poemas produzidos pelos cantadores e repentistas, pode-se dimensionar as possibilidades que as contribuições fonéticas abrem na produção de poesia. Apresentamos uma série de exemplos retirados de obras que cobrem boa parte do território nacional ${ }^{15}$.

É importante notar que os métodos utilizados pelos pesquisadores na transcrição dos versos não são sempre rigorosos, dependendo, muitas vezes, da memória do folclo-

15 Às divisões por linguajares regionais (cf. Nascentes, 1953, pp. 18-26), preferimos um agrupamento de acordo com as referências regionais encontradas nos títulos e subtítulos das obras consultadas. Os exemplos foram encontrados nos estudos pioneiros de Magalhães, Celso de. A poesia popular brasileira. Rio de Janeiro, Biblioteca Nacional, 1973, de Romero, Sílvio. Cantos populares do Brasil. Rio de Janeiro, José Olympio, 1954, e de Moraes Filho, Mello. Cantares brasileiros: cancioneiro fluminense (parte poética). Rio de Janeiro, Livraria Cruz Coutinho, 1900; nos estudos de abrangência nacional, como os de Gallet, Luciano. Estudos de folclore. Rio de Janeiro, Carlos Wehrs,1934; de Silva, Simões. Fragmentos de poesia sertaneja. Rio de Janeiro, Gráfica de Jornal do Brasil, 1934; de Araújo, Alceu Maynard. Folclore Nacional. São Paulo, Melhoramentos, 1964; e de Andrade, Mário de. Ensaio sobre música popular brasileira. 3. ed. São Paulo, Martins Fontes, 1972. Alguns exemplos, representativos das cantorias do Norte, foram retirados do trabalho de Salles, Vicente. Repente e Cordel: literatura popular em versos na Amazônia. Rio de Janeiro, FUNARTE, 1985. Uma grande parte dos textos provém de estudiosos da poesia popular do Nordeste como Carvalho, Rodrigues. Cancioneiro do Norte. 3. ed. Rio de Janeiro, INL,1967; Mota, Leonardo. Violeiros do Norte . São Paulo, Monteiro Lobato, 1925, Cantadores. 2. ed. Rio de Janeiro, Ed. A Noite, 1953, e Sertão Alegre. Rio de Janeiro: Ediouro, 1968; Cascudo, Luís da Câmara. Violeiros e cantadores. Rio de Janeiro, Ediouro, 1970 e Dicionário do folclore brasileiro. 9. ed. Rio de Janeiro: Ediouro, s.d.; Coutinho Filho, F. Violas e Repentes. São Paulo, Saraiva, 1953; Campos, Eduardo. Cantador, musa e viola. Rio de Janeiro, Americana, 1973; Batista, Sebastião Nunes. Poética popular do Nordeste. Rio de Janeiro, Casa de Rui Barbosa, 1982. Wilson, Luís. Roteiro de velhos cantadores e poetas populares do sertão. Recife, Centro de Estudos de História Municipal, 1985. Ayala, Maria Ignez Novais. No arranco do grito. São Paulo, Ática, 1988. . Cocos: alegria e devoção. Natal: EDUFRN, 2000. A poesia da bacia do São Francisco está representada pelas obras de Trigueiros, Edilberto. A língua e o folclore da Bacia do São Francisco. Rio de Janeiro, FUNARTE/Casa de Rui Barbosa,1977. Azevedo, Téo. Cultura popular do Norte de Minas. São Paulo, Top Livros, 1979.e Souza, Oswaldo de. Música folclórica do Médio São Francisco - Vol. I. Rio de Janeiro, MinC, 1979. . Música folclórica do Médio São Francisco - Vol. II. Rio de Janeiro, MinC, 1980; A produção poética do Centro-Oeste foi coligida, sobretudo, por BRASIL, Americano do. Cancioneiro de trovas do Brasil Central. 2. ed. Goiânia, Oriente, 1973. As rimas caipiras foram colhidas nos trabalhos de Amaral, Amadeu. 0 dialeto caipira. São Paulo, "O Livro", 1920. . Tradições populares, . São Paulo, IPÊ, 1948., Lima, Rossini Tavares de. Folclore de São Paulo. 2. ed. São Paulo: Ricordi, 1954., Bandecchi, Brasil. Romanceiro Paulista. São Paulo, Obelisco,1962., Pires, Cornélio. Sambas e cateretês. São Paulo, Unitas, s.d., Tonico e Tinoco. Da beira do Tuia ao Teatro Municipal. 2. ed. São Paulo, Ática, 1984. , e Sant'anna, Romildo. A moda é viola: ensaio do cantar caipira. São Paulo, Arte e Ciência, 2000. As rimas do Sul, por fim, foram retiradas de Meyer, Augusto. Guia de Folclore Gaúcho. Rio de Janeiro, Aurora, 1951. e, sobretudo, de Lopes Neto, J. Simões. Cancioneiro Guasca.2. ed. Rio de Janeiro, Globo,1960. 
rista ou de sua interpretação. Entretanto, muitos desses estudos são hoje as formas conhecidas, reproduzidas, de cantos populares tornando-se, assim, parte do cancioneiro popular brasileiro. Para a análise das rimas, deve-se, contudo, considerar outras fontes, como as descrições lingüísticas dos falares regionais.

É, também, necessário verificar que o modo de registro dos textos varia de folclorista para folclorista. Basileu Toledo França ${ }^{16}$, por exemplo, ao comentar a obra de Americano do Brasil, assinala "a maneira inteligente com que foi elaborada, fugindo ao registro fonético da língua dialetal”; assim como fizeram os primeiros pesquisadores, dentre os quais Sílvio Romero. Já Cornélio Pires - considerado por Mário de Andrade ${ }^{17}$, um "observador agudo, das poesias e dos diferentes processos de poética cantada dos caipiras" apresenta os versos: "conservando-lhes as corruptelas, brasileirismos, defeitos de rima e, muitas vezes, má metrificação, para não lhes tirar o sabor especial e a cor local”. Essa variação na forma de registro da poesia cantada popular faz com que não seja possível fiar-se cegamente nas transcrições escritas encontradas nos livros, uma vez que, em um mesmo autor, o modo como as "corruptelas" são escritas ou destacadas (itálicos, aspas, negritos) variam consideravelmente, mesmo em autores como Cornélio Pires. Por exemplo, na moda "Uma briga no Veado", há a seguinte estrofe:

Dia 20 de janeiro / Foi dia de mau destino

Lá na capela do Veado / Vi o povo reunindo ;

$\mathrm{Na}$ hora que eu cheguei / Eu ouvi toque de sino

o padre dizia a missa, / O povo estava ouvindo

Nela, Cornélio Pires ${ }^{18}$ escreve ouvindo e reunindo que, por sua vez, "rimam" com destino e sino. Ora, Amadeu Amaral ${ }^{19}$ nos ensina que, no dialeto caipira: "a consoante $d$ cai, quase sempre, na sílaba final das formas verbais em ando, endo, indo"; fato que o próprio Cornélio Pires registra na escrita de outros poemas (todos com rimas em -ano), como o "A.B.C. do solteirão":

Bem queria me casá / Quando eu tinha vinte ano, Eu ainda era bobo / Não conhecia os engano ; Fui feliz, não me casei, / Livrei de andá penano.

16 Americano do Brasil, 1973, p.LVIII.

17 Andrade, 1972, p.187.

18 Pires, s.d, p.343.

19 Amaral, 1920, p.27.

107 revista do ieb n 43 set 2006 
Acrescentamos que, no repertório caipira, há exemplos de rimas em -ino, como na famosa "0 menino da porteira", ou ainda na moda de viola "Violeiro", de Tonico e Tinoco ${ }^{20}$ :

Fiquei véio aqui na roça, passei a vida carpino

Canto moda recordando o meu tempo de minino

A provável irregularidade na escrita, mesmo na obra de um "observador agudo" como Cornélio Pires faz com que nos perguntemos se ele, ao registrar a rima cabocro com coco/choco/loco, não se esqueceu de omitir o $r$, uma vez que, como assinala Antenor Nascentes ${ }^{21}$, o desaparecimento da vibrante é corrente na fala popular em encontros consonantais: negro-nego, compadre-cumpade; ou se, como assinala Amadeu Amaral ${ }^{22}$, no dialeto caipira, a forma é mesmo cabocro e não cabôco, esta, uma forma "estranha a S.P.". De todo modo, no Nordeste, mesmo entre os mais "cultos" repentistas, é recorrente o uso de cabôco ${ }^{23}$.

Enfim, como nosso objetivo é ampliar ao máximo as possibilidades rímicas, ainda que essas sejam características de uma única região do país e como não se trata, neste artigo, de aprofundar a discussão sobre a qualidade e a precisão das reproduções escritas dos cantos populares, limitamo-nos aos exemplos em que as marcas da fala foram reproduzidas nas publicações ${ }^{24}$.

\section{Contribuições da poesia popular para o rimário brasileiro}

Como assinalamos acima, a distinção entre consoantes puras e soantes permite-nos agrupar as transformações fonéticas de uma forma que nos parece mais clara, pois aproxima os casos mais recorrentes e producentes no rimário popular.

\section{A) VOGAIS \\ Vogais simples \\ As vogais simples podem ser substituídas ou inver- tidas, originando rimas como:}

20 Tonico e Tinoco, 1984, p.126.

21 Nascentes, 1953, p.55.

22 Amaral, 1920, p. 99.

23 Tanto é que Batista (1982, p.15) assinala a existência de um gênero poético, chamado "Brasil-Caboclo", em que sistematicamente explora-se as possibilidades rímicas em -ôco. Cf. também Ayala, 1988, p.131.

24 Uma proposta de reescritura de poemas colhidos pelos folcloristas com base em estudos lingüísticos é um campo de estudos a ser explorado e um instrumento de reconhecimento da produtividade da língua oral brasileira. 
- ime = ume. Marroquim ${ }^{25}$ colhe o exemplo:

No dia que o nego casa / Deve botá seu rijume

As moça é como as navaia / Fino ou grosso tem seu gume

- omo = ome. Em um coco baiano da bacia do São Francisco ${ }^{26}$ :

O rei da casa é o home

O rei da laranja é o gome

- ume = umo. Como no poema "A Caipora"27:

Mais, ai Maria, o phantasma / Veio bater no meu rumo, Rindo-se muito e dizendo: / Dá-me uma pêia de fumo. E c'o uma faca afiada / Batendo em mim com seu gumo.

- ude = uda. Assim, no "ABC do povo da Caatinga"28:

$Y$ - pissilone é letra grega / pra home que estuda ; gente daquela catinga / já vi cabeça mais ruda ; pra quem tem atividade / chega hoje, amanhã muda.

\section{Ditongos}

0 processo mais produtivo envolvendo as vogais é a absorção do $i$ e do $u$ nos ditongos. Esse processo, na poesia culta, como assinala Câmara $\mathrm{Jr}^{29}{ }^{29}$, resume-se aos ditongos ie e $u o$, em posição postônica. Há, ainda, na poesia popular:

- aulo = alo. Como em "Triste Partida"

Eu vendo meu burro, meu jegue, meu cavalo,

Nós vamo a Sã Palo

Vivê ou morrê.

- ânsia = ança. Num desafio com Neco Martins, o cego Francisco Sales, por ter desconsiderado o colega, faz mea culpa ${ }^{31}$ :

Colega Neco Martins, / Faltou-me esta lembrança, Que hoje peço desculpa, / Dessa minha ignorança

- égio = éjo. Como nos versos do piauiense chamado Cão Dentro $^{32}$ :

25 Marroquim, p. 1934, p.41.

26 Trigueiros, 1977, p.80.

27 Carvalho, 1967, p.158.

28 Souza, 1980, p.136.

29 Câmara Jr., 1953.

30 Assaré, Patativa do. Inspiração nordestina. Rio de janeiros, Borsoi, 1956, p.5.

31 Carvalho, 1967, p.244.

32 Mota, 1968, p.212. 
Derrota de home é muié, Calango pintado é Tejo;

Traira é passo da lama, / Caçote é passo do brejo...

Este caboclo Cão Dentro / Pra cantar tem prevelejo!

0 mesmo ocorre em sextilhas caipiras como "0 patrão veiaco" em que se rima preveléjo/coléjo/brejo.

- ênção = ença. No par bênção-bença, como no Gabinete:

Sinhô dono da casa, dê licença

Para eu dá nesse cabra em seu salão,

Fazê ele beijá a minha mão

De joêio pedi a minha bença!

- ência = ença . Em uma cantoria Daudeth Bandeira declama:

Cazuza bebeu cachaça / i uns bebu pa fazê graça / lhi pegaru na dispensa

i raparu a cabilera / du donu da residença

- êmea = eme. Como no verso colhido por Anselmo

Vieira $^{33}$ em que, num desafio com Chica Barboaa, um

cantador piauiense lhe disse:

Eu sou canguçu macho, / Tu és canguçu feme...

Se piso em riba da serra, / Em baixo lajero treme!

- éria = era. No "ABC dos Casados" ${ }^{34}$ :

Çalvo em reservos / os que trabalha prospera

pra não fica na putaria, / pra não fica na miséra.

- ério = éro. Na "Cantiga do Vilela", cego Sinfrônio canta a seguinte resposta do delegado ante a resistência de Vilela em se entregar à polícia ${ }^{35}$ :

Vilela tem paciença, / Vigie que eu falo séro:

Desta feita você segue, / (Isto eu quero porque quero)

Ou em corda p'r'a cadeia / Ou em rede pro cimitéro

- $\quad$ ícia = iça. Zé Limeira, com sua lógica própria, canta ${ }^{36}$ :

Jesus nasceu neste mundo, / Só para fazer justiça;

Com doze anos de idade, / Discutiu com a doutoriça;

Com vinte anos depois, / Sentou praça na puliça.

- ício = iço. No "Romance do Boi da Mão de Pau", de Fabião das Queimadas ${ }^{37}$ :

33 Mota, 1953, p.211.

34 Souza, 1980, p.121.

35 Mota, 1953, p.39.

36 Ayala, 1988, p.134.

37 Cascudo, 1970, p.89. 
Pegaram a me aperriar, / Fazendo brabo estrupiço,

Fabião na casa dele, / Esmiuçando por isso,

Mode no fim da batalha / Pude fazê o serviço...

- ória = ora. Fabião das queimadas, descrevendo a vaquejada canta ${ }^{38}$ :

Dê-me lembrança ao cavalo / Do senhor José Lebora, Qu'eu sei que é corredô / Pra chegá boi não demora, Mas porém nas minhas unha / Não pôde cantá vitora...

- ório = oro. Bernardo Cintura, na época em que faltava troco no mercado, imaginou um caipora governador, $\mathrm{Fu}-$ trica, sobre qual escreveu a seguinte décima ${ }^{39}$ :

No lugá aonde eu moro / Lastimando a triste sorte, Tem dia que peço a morte, / Padeço, gemendo, choro... Deu doze preparatoro

No culejo qui estudô... / É formado dotô...

Nesse país brasileiro / Não há quem troque dinheiro...

- Futrica é governadô.

Merece atenção o processo de absorção do $i$ dos ditongos ia e io, precedidos de nasal, uma vez que ocorre, além da absorção, a palatalização, como em Antônio- $A n$ tonho; motivo pelo qual enumeramos os exemplos juntamente com as nasais.

0 desaparecimento de vogais postônicas faz com que algumas proparoxítonas percam a sílaba postônica. Tratase de um processo já identificado na passagem do latim para o latim vulgar ${ }^{40}$. Na poesia popular esse processo permitiu o surgimento das rimas:

- âmpago = ampo. No final do poema "Inverno"41, cantase a tempestade:

(... ) Abre e fecha o relampo

Estremece o campo

E corre a zelação

- írito = ito. 0 menestrel João Mendes, ao descrever a chegada de Padre Cícero a Juazeiro, canta $^{42}$ :

Achou tudo acorrentado / Pelos laço do Maldito, E Satanaz ensinando / Bebê, Mata, dizê dito, P'ra nos levá p'r'o inferno, Condená o nosso esprito.

38 Idem, p.83.

39 Carvalho, 1967, p.383.

40 cf. Marroquim, 1934, p.43.

41 Idem, p.128.

42 Mota, 1953, p.173.

111 revista do ieb $\mathrm{n} 43$ set 2006 
- ízimo (ou íssimo) = ismo. Na "Obra de Ricarte" ${ }^{\text {"3 }}$, há a seguinte quadra:

Se pego 10 de pau, / É conta do algarismo, Foi conta que Deus deixou / De 10 se pagar o dismo

- ôncavo = onco. É rima produzida por Preto Limão em resposta a Bernardo Nogueira ${ }^{44}$ :

Me chamam preto limão, / sou turuna no reconco, quebro jucá pelo meio, / baraúna pelo tronco, cantador como Nogueira / tudo obedece meu ronco. Enfim, pode surgir um novo ditongo, permitindo, sobretudo, rimas em:

- ença = ência. Em uma congada mineira, durante a Embaixada, representação dramática das lutas do Rei do Congo, Roldão dirige-se ao General ${ }^{45}$ :

Ò, meu nobre generá, / chega na minha presência pra nóis tê uma conversa / debaxo de uma consciência.

\section{b) CONSOANTES}

Tratamos aqui exclusivamente das transformação das consoantes puras, isto é, os processos em que não estão implicadas laterais, vibrantes e nasais.

0 mais comum, presente em todas as regiões do país, é o apagamento do $s$ final (aférese), não só dos plurais, mas de vocábulos terminados em $s$, produzindo rimas como, por exemplo:

- enos = eno. Como nos versos de José $\operatorname{Matos}^{46}$, em que pede na feira:

Amigo, dê-me um preá

Seja grande ou pequeno,

Prometa sequer ao meno

Amigo, dê-me um preá.

- ovas = ova. Como no coco dos cantadores de Camalaú ${ }^{47}$ :

Meu pé de milho arvoredo / que todo ano renova

São João diga a São Pedro / que me mande boas nova'

43 Carvalho, 1967, p.196.

44 Cascudo, 1970, p.180.

45 Araújo, 1964, p.249.

46 Campos, 1973, p.45.

47 Ayala, 2000, p.211. 
Lembramos que o som [s] final pode ser escrito com $z$ e, muitas vezes, como vimos, ditonga-se a vogal que o precede (paz-pais, três-trêis, voz-vóis, luz-luis). Na poesia popular, com a supressão do $s$ chega-se aos seguintes ditongos:

- ais = ai. No coco de Seu Tuninha ${ }^{48}$, temos:

Tuninha aonde canta / O povo dali não sai Os pagão que tá chorando / Se cala não chora mái

- az [ais] = ai. Como no coco de Dona Odete ${ }^{49}$ :

A menina de Goiana / não se alumeia com gái s'alumeia com a catemba / o coqueiro quando cai

- ez [eis] = ei. Comum nas modas de raízes, como nesta de Tonico e Anacleto Rosas ${ }^{50}$, em que um caboclo reage ao assédio sexual de um ricaço contra sua mulher, logo depois de ouvir a história contada pela mulher em prantos:

Eu piquei de espora meu burrão tordio / rodei corrupio, pa trais eu vortei.

Eu cheguei na praça, lá estava o ricaço, / contando com graça o que ele fei.

Eu já fui chegando e o cabra surrando./ Puxou o revórve, mai tempo não dei.

\section{c) SOANTES}

Parte importante dos processos fônicos dos falares populares envolvem as soantes. Alguns deles são específicos das nasais e das laterais como a despalatalização. Da mesma forma, há uma série de processos que são comuns às laterais e vibrantes.

\section{Laterais}

A absorção do $l$ em tônica final produz rimas com todas as vogais. Mattoso Câmara (1953) já havia notado a assimilação da u em ul (azul=azuu=azu), processo semelhante se dá com outras vogais, formando um conjunto expressivo de rimas encontradas em todas as regiões do país.

- al = á. Contribuição que atravessa os séculos, chega aos dias de hoje, por exemplo, no côco de Seu Roque, de Cabedelo $/ \mathrm{PB}^{51}$ :

48 Idem, p.113.

49 Idem, p.186.

50 Tonico e Tinoco, 1984, p.154.

51 Ayala, 2000, p.151. 
Ô viva ano viva rei / ô viva noite de natá

As menina me pergunta / quer ir ou quer que eu vá

- el = é. Como na resposta dada pelo vaqueiro Boa Raça em um desafio ${ }^{52}$ :

Já fui linha de meada / E hoje sou carreté, Já fui minino, sou home / Só me farta muié.

- $\quad$ il $=\mathrm{i}$. Como neste improviso de feira referente ao cangaço ${ }^{53}$ :

Em cima daquela serra / Tem caju e cajuí, Tem muita moça bonita, / E cabra bom no fuzi...

- ol = ó. É o caso da ariramba, antigo batuque amazônico em que se canta ${ }^{54}$ :

Eu quero, meu bem eu quero! Eu quero contigo só... Deitado na minha rede, / Coberto com meu lençó!...

Ou ainda no lundu "O pescador", de Xisto Bahia e Artur Azevedo ${ }^{55}$ :

Mais cuidado sinhazinha, / Nunca pesque um peixe só Lance a três a mesma linha, / Pesque seis no mesmo anzó

- ivel = ive. Pode se suprimir o $l$ final como no verso de Tião Carreiro e Pardinho ${ }^{56}$ :

Ai, pra aprendê a cantar de viola / Primeiro estudo que eu tive:

Aprendi com violeiro véio / Que fazia moda impossive.

Às vezes o processo de absorção envolve, não apenas a lateral, mas vogais postônicas que precede, ou seja:

- ólo = ó. Como na "Roda de Tropeiro" da bacia do São Francisco ${ }^{57}$ :

O diabo da véia / Não anda só, Com um chifre de boi / E um mocotó, Com cabaça de mé / A tiracó.

52 Silva, 1934, p.76.

53 Carvalho, 1967, p.103.

54 Salles, 1985, p.62.

55 Moraes Filho, 1900, p.30.

56 Sant'Anna, 2000, p.222.

57 Trigueiros, 1977, p.163. 
Há, também, alguns encontros consonânticos em que não se pronuncia a lateral, originando as rimas:

- ifle $=$ ife Como no verso do Cego Aderaldo ${ }^{58}$, em que descreve a luta do movimento revolucionário cearense de 1914, durante o qual:

O menino ainda disse: / - "Eu não temo êsses patife! Seu Emílio Sá bem sabe / Que eu, enquanto tivé rife De coração de jagunço, / Faço urubu comê bife!"

- oclo = oco. Caso acima comentado e que exemplificamos aqui com o coco de Dona Domerina ${ }^{59}$ :

Botei a mão na cabeça / valha-me rei dos caboco agora eu sei que morro / na ilha do arranca toco.

A despalatalização do $l h$ é muito recorrente e produz grande número de rimas em:

- alha = aia. Na sextilha do cego Sinfrônio ${ }^{60}$ :

Eu, atrás de cantadô, / Sou como vento por praia Sou como junco por lagoa, / Como fogo por fornaia Como piôi por cabeça / Ou pulga por cós de saia

- alho = aio. No samba paulista "Subi pelo tronco"61: Subi pelo tronco / Desci pelo gaio; Marica, me acode / Sinão eu caio!

- elho = êio. Há o canto dos pescadores da Barra ${ }^{62}$ :

Pescadô qu'está pescando / pesca na pedra do meio me pega aquela menina / vistidinha de vermêio

- elha = êia. Usufruindo desta possibilidade rímica, um apaixonado entoa ${ }^{63}$ :

Numa tarde de verão, / na noite de lua cheia se eu contá os gostos que tive, / me ferve o sangue nas [veia.

Namorei teus olhos pretos / por baixo da sobrancêia. Se eu for preso nos teus braços, / não precisa mais [cadeia.

58 Mota, 1953, p.100.

59 Ayala, 2000, p.156.

60 Mota, 1953, p.16.

61 Andrade, 1972, p.90.

62 Souza, 1980, p.45.

63 Amaral, 1948, p.110. 
- élha = éia. No folclore paulista ${ }^{64}$ :

A minha destinta platéia

Pá contá o que eu tenho na idéia

Já vortei na toada véia

- ilha = ia. Em um romance de Fabião das Queimadas ${ }^{65}$ :

Quando vi Antonho Ansermo, / No cavalo Maravia, Fui tratando de corrê, / Mas sabendo que morria... Saiu de casa disposto, / Se despediu da famia.

- ilho = io. Fabião das Queimadas, descrevendo a vaquejada, canta ${ }^{66}$ :

Dê-me lembrança a Ovídio, / Filho de senhor Macio, Que também gostou de ver / A carreira do nuvio E ao camarada dêle, / Chamado Mané Bazío

- $\quad$ alhe $=$ ai. Como na trova ${ }^{67}$ :

Aribu quand'infeli / Não há pau que o agazai; S'atrepa in riba da péda, / A péda imbola, êle cai.

- olhe = ói. A negra Chica Barroza, em um desafio disse ${ }^{68}$ : Os homens possuem as terras, / Os ruins por si se destrói Segura lá teus calções / Aperta, estira, encurta, encoe.

- ulho = ui. No "ABC do povo da caatinga"69:

Chorando eles tudo véve, / devendo o que não pissúi; andam todos assombrado / quando é tempo de barui o culpado é eles mesmo, / tudo quando vê influi.

Note-se que o fonema mais próximo do [l] é, em português o [r], fato que leva Nascentes ${ }^{70}$ a afirmar: "A consoante mais vizinha da vibrante $l$ é a vibrante $r$ ". No mesmo parágrafo, o autor também assinala: "Consoante seguida de $l$. Tal como na passagem do latim para o português, o $l$ se muda em $r$. (...) 0 fato se passa também em Portugal (...). Por conseguinte está dentro das tendências da língua"; o que na

64 Lima, 1954, p.19.

65 Cascudo, 1970, p.89.

66 Idem, p.83.

67 Carvalho, 1967, p.103.

68 Carvalho, 1967, p.182.

69 Souza, 1980, p.136.

70 Nascentes, 1953, p.53. 
poesia popular produz novas rimas como, por exemplo, estas em que se transforma a lateral final:

- $\quad$ al $=$ ar. Comum nos falares caipiras, como nestes versos $^{71}$ :

Na estação de Pirambóia, / num me acostumei c'os ar; Tem a estação de Sagrado... / Pra mim é um lugar sem sar.

- il = ir. Na toada "Caipira é vosso amigo" de Capitão Furtado $^{72}$, encontra-se:

Se a Nação necessitá que o caipira vai servir, breganhando sua enxada por um sabre e um fuzir, o caipira corajoso, com orguio vai seguir, pra lutar e defender sua Pátria, o Brasir.

- ol = ór. É também caipira essa rima, enontrada nas "Queixas do boi"73:

Eu passei esses trabalhos, / uns grandes outros maior às quatro horas da tarde / tive de casco p'ra o sor.

Também usual nas modas caipiras de raíz é a transformação de laterais postônicas de vocábulos paroxítonos, criando rimas feito estas:

- alta = arta. Como na moda "Os velhos de agora"74:

Aonde vóis tivé / Mi iscreva ua carta;

Mi manda lembrança / Também teu retrato ;

Aonde nóis incontra / É beijo e abraço.

Pra vóis ficá sabeno / Que amor não me farta.

- alto = arto. Na mesma moda "Os velhos de agora", há:

Os véio de agora / São muito veiáco, Veve dando pulo / Veve dando sarto;

Pula pra riba, / Que pula bem arto, Êle cai de costa / E destronca o quarto

- olta = orta. Como na moda catireira "As moça caipira"75:

Pois as moça caipira / Inda tem as perna torta, Encontra a gente na estrada / Ela esconde ou corta a vorta.

71 Pires, s.d., p.65.

72 Tonico e Tinoco, 1984, p.196.

73 Amaral, 1948, p.76.

74 Pires, s.d., p.330.

75 Idem, p.296. 


\section{Vibrantes}

Como todas as consoantes finais, o $r$ tende a desaparecer, ampliando o vasto leque de rimas terminadas em vogais, como:

- $\operatorname{ar}=$ á. A supressão no final de vocábulo pode, inclusive, atingir a semivogal de ditongos, como na toada "Minas Gerais" de Raul Torres e João Pacífico ${ }^{76}$ :

Mas quá o que eu não me esqueço não, / pro meu sertão quero vortá

Quero morrê naquele meu sertão, / quero morrê lá em Mina Gerá.

- er $=$ ê. Como neste exemplo gaúcho ${ }^{77}$ :

O tatu subiu no pau!... / É mentira de você:

Só que o pau fosse deitado / Isso sim podia sê...

- $\quad$ er = é. Como na quadra popular paulista sobre o cafép $^{78}$ :

Eu quisera sê penera / na coieta do café,

Só pra anda sipindurado / na cintura das muié.

- ir = i. Como na quadra, composta em Santarém, durante uma desfeiteira, jogo de sorte comum nos bailes amazônicos, em que aquele que, interrompida a música da orquestra, encontrar-se diante da mesma, compõe para o seu par, em geral, versos injuriosos como estes compostos por uma dama que diz a seu parceiro ${ }^{79}$ :

Em cima daquela serra / tem um pé de murici quando olho pra tua cara / dá vontade de tussi.

- $\quad$ or $=\hat{\text { o. }}$. Como nestes versos de Cego Sinfrônio ${ }^{80}$ :

Me responda seu Jerome, / Aonde sois moradô...

Cumo se chama seu pai, / Mãe madrinha e avô.

0 desaparecimento do $r$ é comum na fala popular em encontros consonantais como:

- astro = asto. Em uma versão do "Rabicho da Geralda"81.

Mandaram buscá um guia / pra ensiná os pasto:

- Sinhô, pr'eu pegá Rabicho / só careço é dá no rasto.

76 Tonico e Tinoco, 1984, p.248.

77 Lopes Neto, 1960, p.22.

78 Bandecchi, 1962, p.43.

79 Salles, 1985, p.82.

80 Mota, 1953, p.27.

81 Souza, 1980, p.95. 
- adre = ade Como no poema depreciativo do negro, em que Mestre Teles, velho pedreiro de Quixeramobim, canta ${ }^{82}$ :

Não quero mais bem a nêgo / Nem que seja meu compáde:

Nêgo só óia p'r'a gente / P'ra fazê a falsidade! Mermo em tempo de fartura / Nêgo chora necessidade

- entro = ento Como no coco de Seu Valdemar - cantadores e dançadores de Camalaú ${ }^{83}$ :

Eu vi a pancada do mar / eu vi a refrega do vento eu vi o barco navegando / mas é Maria que vem dent'o

- itro = ito. Feito na moda-de-viola "Dexei um vendero rico" ${ }^{84}$ :

Um dia dêste passado, / Dexei um vendero rico;

Comprei um quilo de arroiz / De toicinho mais de lito Comprei um saco de sal / Daqueles mais piquitito; Eu vim alegre pra casa / Vim pulano e dano grito.

\section{Nasais}

Um dos processos mais recorrentes é a desnasalização em final de vocábulo, o que permite as seguintes rimas:

- agem = age. Como nesta moda-de-viola de Vieira e Vieirinha ${ }^{85}$ :

Levantei um dia cedo, / Arrumei minhas bagage, Eu fui pegá a minha besta / Pra fazê minhas viage. Vesti o carção de bombacha / Por eu gostá desse traje, Laço bão tá na garupa / E na cintura uma ferrage, No caso de precisão / Das veiz a gente reage!

- omem = ome. Ocorre de norte a sul, como no exemplo gaúcho ${ }^{86}$ :

Dentro de meu peito tenho / Uma dor que me consome: Ando cumprindo meu fado, / Em trajes de lobisome.

- ontem=onte. Ocorre nesta xácara, "0 capitão do Navio", entoada por Anselmo Vieira ${ }^{87}$ :

82 Mota, 1953, p.83.

83 Ayala, 2000, p.211.

84 Pires, s.d., p.129.

85 Sant'Anna, 200, p.121.

86 Meyer, 1951, p.97.

87 Mota, 1953, p.206.

119 revista do ieb n 43 set 2006 
Chega os soldado em Palaço / E a muié falou de fronte:

"Soldado, agora é que quero / Que vocês todos dois conte Aquela tristonha históra / Que vocês contáro onte.

- ordem = orde. Em um desafio, Tonico e Tinoco cantam ${ }^{88}$ :

Pau podre não dá cavaco, desgraça pouca é desorde. É certo aquele ditado: cachorro latiu, não morde.

- $\operatorname{aram}=$ aro. Fabião das Queimadas, ao descrever a vaquejada ${ }^{89}$ :

Lembrança aos vaqueiros todos / Que vinham em bons [cavalo, Que correm atrás de mim / Mas porém não me pegaro E eu dei tabaco a todos / Na presença do Vigaro....

- $\mathrm{im}=\mathrm{i}$. Fenômeno com marcas claramente medievais, aparece no "Bernal francês", neste caso, publicado em 1873 por Celso de Magalhães ${ }^{90}$. É uma rima não registrada na poesia de cantadores.

Vive, vive, cavaleiro, / Vive tu que eu já morri; Os olhos com que te olhava / De terra já os cobri. Boca com que te beijava / Já não tem sabor em si. O cabelo que entrançavas / Jaz caído ao pé de mi, Dos braços que te abraçavam / As canas velas aqui! Vive, vive, cavaleiro, / Vive tu que eu já morri;

Note-se o curioso exemplo encontrado na moda de viola "Dexei um vendero rico", em que o narrador, ao chegar em casa, encontra a mulher tão furiosa que o trata assim:

Me deu na perna cum pau, / quase me quebrou os cambito Botei a boca no mundo, / Berrava quinem cabrito: - Me vaia nossa senhora! Me acuda São Benedito! A muié qué mi matá, / Só pramode eu sê famito.

- uma = ua. Processo encontrado na moda "Os gafanhotos" ${ }^{\prime 1}$, em que se descreve uma invasão dos saltões e que permite as seguintes recorrências fônicas:

Na cidade de São Paulo / Diz que deu pra enxê a rua;

Que tapou a luz do sol, / E tapou a luz da lua;

Tá escrito no jorná, / Não é mentira nenhua

88 Tonico e Tinoco, 1984, p.171.

89 Cascudo, 1970, p.83.

90 Magalhães, 1973, p.59.

91 Pires, s.d., p.335. 
Quanto à desnasalização, note-se, enfim, que o apagamento da nasal final, somada ao apagamento do $s$ final, permite inusitadas rimas em -ôme ${ }^{92}$, como em:

Besta nasci, besta sou, / Apois besta é o meu nome, Mas besta é os vaqueiro / Qui nasceru sendo home, Porque pensavum qu'eu era / O gado da Joana Gome...

Outro fenômeno importante é o apagamento de vogais em posição postônica, em vocábulo com tônicas nasalizadas. Note-se que a supressão pode ou não ditongar a tônica nasal; daí surgem rimas como:

- inho = im. Rima rara hoje, comum nos compêndios de Leonardo Mota, produz versos como os da "embolada de duas voltas" de Manoel Moreira ${ }^{93}$ :

Eu vim de longe, / Do centro das Alagoa Já andava quase à-toa, / Sem dinheiro pra passá

Passei fome, / Passei sede nos camim E já vendo a coisa ruim, / Me vali dêste ganzá

Vale acrescentar a composição do vaqueiro Miguel Fonseca $^{94}$, em que o cavalo "Cangueiro", ao saber que seria vendido, lamenta-se:

O mundo nunca se acaba, / Eu confirmo ser assim :

O tempo vai e não volta, / É isso que eu acho ruim. (...) Passei a noite pensando / No que seria de mim. Pra me despedir dos campos / Levantei-me bem cedim...

- anhe = ãe. Ayala ${ }^{95}$ comenta que: "Outro caso de rima por identidade fonética é a que ocorre entre palavras como mãe e apanhe, quando esta última passa por um processo de despalatalização, conservando-se nasalada. Este processo é também comum na linguagem coloquial nordestina”. Encontramos o seguinte exemplo, na réplica de Diniz Vitorino a Severino Feitosa ${ }^{96}$ :

Meu esposo bem jovem me encontrou é bem justo que eu a ele não estranhe no meu ventre sagrado que é de mãe mais um filho sublime se gerou

92Cascudo, 1970, p.87.

93 Mota, 1968, p.129.

94 Mota, 1925, p.117.

95 Ayala, 1988, p.131.

96 Idem, p.197.

121 revista do ieb $n 43$ set 2006 
- $\quad$ anho = ãe. Como na embolada de Terezinha e Lindalva ${ }^{97}$ :

T- $\quad$ Ai num queira me maltratar

e que num tô lhe maltratando

é o fumo que tá entrando

e você vai deixar entrar

$L$ - É data dia mês e ano

vai entrar na tua mãe

que a velha nem toma bãe

nem lava o maracujá

- $\mathbf{o m}=$ ão. A transformação de bom em bão aparece com freqüência nas modas-de-viola caipiras e em poemas populares do Centro-Oeste, como na "Décima do Bico Branco", poema do ciclo do gado goiano ${ }^{98}$ :

Esses vaqueiros chegaram / Montados em cavalos bão Trouxeram cachorros, laços, / As aguilhadas na mão.

Note-se esta rima rara, no momento da coroação do rei e da rainha de Moçambique de Cachoeirinha, quando o Mestre canta ${ }^{99}$ :

Nosso rei São Benidito / me mandô avisá, irmão, prá dançá bem no compasso, / pelo paia, precura o são

Há, também, a supressão de consoantes, como o $g$ e, sobretudo, o $d$ dos gerúndios.

- ando = ano. Há inúmeros casos em todo o território nacional. Um dos mais emocionantes é o da primeira estrofe do "Recorte do sonho"100:

Esta noite eu sonhei / Que eu era um beija flor,

Tava nos ar avoano, / Procurando o meu amor.

Eu vi meu bem / Lá no terreiro...

Dei um beijinho / Sai ligeiro.

Bateno as asas lá fui voano

Cortano os ar quiném aeroplano.

- endo = eno. É o que ocorre nesta quadra de "Saída do Divino", cantada em Itu ${ }^{101}$ :

o Devino se dispede / dos grande e dos piqueno, que os ânju lá do céu / seus nome tão escreveno.

97 Ayala, 2000, p.94.

98 Brasil, 1973, p.161.

99 Araújo, 1964, p.361.

100 Pires, s.d., p.204.

101 Araújo, 1964, p.87. 
- indo = ino. Em Bom Jesus da Lapa, num "Reis da Porta"102, canta-se:

ô de casa, ô moradô, / acorda se tá drumino! Nóis viemo cum fervô / festejá o Deus Menino

- igna = ina. Como na "Décima da mulher rica e da mulher pobre", no momento em que a rica é tomada por uma praga fatal, devido à sua falta de caridade ${ }^{103}$ :

Dai Leonarda saiu, / E foi ver uma capina, Quando pra casa voltou / Estava já com a malina

- igno = ino. Leia-se o "Coco de Praia" intitulado "Menina me dá teu remo"104:

Olelê minha senhora / De que chora esse menino Ele chora de malino / Somente pra perreá

A absorção do $i$ dos ditongos ia e io, quando precedidos de nasal, é muitas vezes seguida de palatalização, produzindo rimas como:

- ônia = onha. Em uma peleja entre Chica Barbosa e Neco Martins, este detratou a adversária da seguinte forma ${ }^{105}$ :

Eu respeitei o oditóro, / A gente de cirimonha Mas infeliz da pessoa / Que não sabe o que é vergonha Por isso nêga, eu agora / Dou-te uma pisa medonha...

\section{Invenção e preconceito}

0 levantamento acima é prova da produtividade da fala popular na criação de um novo conjunto de possibilidades rímicas, o que amplia o leque de rimas na língua portuguesa. Entretanto, os poetas populares que produzem textos em que essas marcas sejam visíveis são, muitas vezes, desconsiderados pelos seus próprios pares como analfabetos, incapazes de utilizar "corretamente" a língua portuguesa. Como assinala Lopes ${ }^{106}$ "a rima entre as palavras amor e chegou é considerada (pelos próprios repentistas) como um indício de analfabetismo". É o que atesta Téo Azevedo ${ }^{107}$ que, ao citar "Exemplo de rimas" afirma que "chalé com mulher" é "rima errada".

102 Souza, 1979, p.58.

103 Brasil, 1973, p.54.

104 Gallet, 1934.

105 Mota, 1953, p.76.

106 Lopes, Gustavo Magalhães. De pés de parede a festivais. Dissertação de mestrado. UNICAMP, 2001, p.44.

107 Azevedo, 1979, p.15.

123 revista do ieb $\mathrm{n} 43$ set 2006 
0 preconceito impresso nesse discurso deve-se ao fato de que esses processos fônicos são marcadamente rurais e/ ou característicos da fala da população analfabeta e, assim, desvalorizada. Como destaca Romildo Sant'Anna ${ }^{108}$ : "A começar pelos constituintes de ordem lingüística, instaura-se a clara divisão de exclusividade da cadeia dominante, representada pelo tope burguês, sobre a maioria dos falantes, discriminada em sua cultura, linguagem e arte".

A oposição rural-urbano, periferia-centro, erradocerto, é uma distinção sócio-cultural, que se dá pela própria esfera de atuação dos cantadores. Assim, a profissionalização e a adaptação ao meio urbano de repentistas contrasta com a posição marginal dos coquistas e dos emboladores, que atuam ainda em esferas rurais, periféricas e não midiáticas. Nos festivais de repentistas, o papel dos coquistas é marginal e não há, de fato, competições e premiações para o gênero. Como se pode notar na fala de Zé Ferreira; em entrevista a Ayala ${ }^{109}$, ele estabelece uma comparação entre o repente e a embolada, na qual: “(...) pode rimar Ceará com cantá e o cantador não pode rimar. Na embolada pode".

Aceita-se essa rima na embolada pois ela é considerada um gênero menor, praticado por pessoas sem estudo. Moreno ${ }^{110}$ observa:

No que diz respeito à situação sócio-econômica, os praticantes do coco, em sua maioria, convivem com [...] falta de habitação, moradias insalubres, carência alimentar, desemprego, luta pela posse da terra e até condições de trabalho de semi-escravidão. [...] Tanto na zona rural como nas cidades, grande parte dos filhos dos coquistas não têm acesso à escola.

Diferentemente dos repentistas e cantadores de moda de viola, os coquistas continuam alijados, apesar do recente sucesso da dupla Caju e Castanha.

Note-se que as condições sociais de produção de bens simbólicos são determinantes, na definição dos padrões lingüísticos. É o que atesta, também, Romildo Sant'Anna ${ }^{111}$ quando assinala as "diferenças notáveis entre os registros de fala" de Vieira e Vieirinha, por exemplo, em relação a Tião Carreiro e Pardinho. "Na cronologia desta última dupla vamos sentir uma paulatina assimilação do "falar correto do

108 Sant'Anna, 2000, p.24.

109 Ayala, 1988, p.130.

110 Moreno, Josane Cristina Santos. "O perfil dos coquistas": Ayala (2000), p. 41-46.

111 Sant'Anna, 2000, p.53. 
outro' em sua fala, à medida em que os artistas interagem nos vários lugares, dos cafundós rústicos do campo aos ambientes mais refinados das cidades". Não se trata aqui de assumir uma postura nostálgica e sim notar o que implica utilizar-se ou não de um falar caboclo.

Salientamos, ainda, que o próprio modo como os textos são registrados indica a postura do antologista diante do texto. Determinados folcloristas, por exemplo, optam por grifar (itálicos, aspas, negritos) os desvios, enquanto outros optam por um registro mais fonético, sem que os processos fônicos sejam destacados. Este é o caso de Leonardo Mota, de Mário de Andrade e de Cornélio Pires e é a postura por nós adotada, ou seja, não se trata de destacar essas marcas e sim de considerá-las integradas ao discurso. Acreditamos, também, que, apesar da existência de "uma diferença grande de registro lingüístico entre os vários locutores"112, a grafia de muitos textos lidos ao longo da pesquisa foi adaptada à escrita em detrimento da rima; o que marca um claro preconceito em relação aos falares populares, uma tentativa de "corrigi-los". Acreditamos ser de grande valia um estudo que se propusesse a reescrever foneticamente esses textos.

Enfim, vários trabalhos lingüísticos como, por exemplo, as análises de Amaral, de Nascentes e de Marroquim, demonstram que a maioria dos processos lingüísticos aqui mencionados explica-se pela própria índole e evolução da língua portuguesa; o que confirma a tese de que a desconsideração desses falares é política e ideológica. Talvez, ao colocarmo-nos diante desses fenômenos, não como desvios e alterações e sim como contribuições e ampliações das possibilidades poéticas da língua portuguesa, estejamos de algum modo contribuindo para que possamos, livres de preconceitos, dimensionar a criatividade dos poetas populares, capazes de utilizar vivamente marcas constitutivas de sua fala.

112 Idem, p.53. 